\title{
PELATIHAN PENGGUNAAN MEDIA PEMBELAJARAN MATEMATIKA PADA MGMP MATEMATIKA SMA KABUPATEN KUBU RAYA
}

\author{
Hartono $^{1}$, Rahman Haryadi ${ }^{2}$, Utin Desy Susiaty ${ }^{3}$ \\ ${ }^{1,2,3}$ Program Studi Pendidikan Matematika, Fakultas Pendidikan MIPA dan Teknologi, \\ IKIP PGRI Pontianak, Jln. Ampera Nomor 88 Pontianak \\ 1e_mail : andra.hartono@gmail.com
}

\begin{abstract}
Abstrak
Kegiatan pengabdian berupa pelatihan penggunaan media pembelajaran matematika untuk guru matematika sma sekabupaten kubu raya. Kegiatan dilaksanakan di Aula Al Fithyan School Kubu Raya Jalan Raya Kakap Pal 7. Peserta dalam kegiatan pengabdian adalah guru matematika yang tergabung dalam MGMP Matematika SMA Kubu Raya. Tujuan dari kegiatan pengabdian adalah: (1) teridentifikasinya konsep-konsep matematika terutama trigonometri yang memerlukan media pembelajaran matematika inovatif untuk memudahkan siswa memahami materi; (2) Meningkatnya pengetahuan para guru tentang media pembelajaran matematika yang inovatif dan memiliki kemampuan untuk mengimplementasikannya dalam kegiatan pembelajaran di kelas. Kegiatan pengabdian telah menambah pengetahuan dan wawasan guru matematika SMA mengenai penggunaan media pembelajaran matematika khususnya trigonometri. Sehingga guru dapat mengaplikasikan penggunaan media pembelajaran tersebut dalam pembelajaran di kelas.
\end{abstract}

Kata kunci: Media Pembelajaran Matematika, Trigonometri

\begin{abstract}
Activities of devotion in the form of training the use of mathematics learning media for math teachers sma sekabupaten highway. The event was held at Al Fithyan School Hall Kubu Raya Jalan Raya Kakap Pal 7. Participants in the dedication activity were math teachers who joined in MGMP Mathematics of Kubu Raya High School. The purpose of the devotion activities are: (1) the identification of mathematical concepts especially trigonometry that require innovative mathematical learning media to make it easier for students to understand the material; (2) Increasing teachers' knowledge of innovative math learning media and having the ability to implement it in classroom learning activities. Devotional activities have increased the knowledge and insight of high school mathematics teachers on the use of mathematics learning media especially trigonometry. So that teachers can apply the use of learning media in learning in the classroom.
\end{abstract}

Keywords: Media of Mathematics Learning, Trigonometry

\section{PENDAHULUAN}

MGMP Matematika SMA Kabupaten Kubu Raya memiliki agenda rutin membahas permasalahan pembelajaran matematika yang dialami guru selama mengajar. Hasil belajar matematika yang masih menjadi tolak ukur keberhasilan 
siswa baik tingkat Sekolah Dasar hingga Sekolah Menengah Atas menunjukkan bahwa matematika masih menjadi standar keberhasilan siswa menyelesaikan suatu jenjang pendidikan. Matematika yang berada di semua jenjang pendidikan ditambah lagi porsi belajar yang lebih besar dari mata pelajaran lain tidak lantas menurunkan tingkat ketidaksukaan siswa terhadap matematika. Permasalahanpermasalahan tersebut merupakan contoh permasalahan yang dimusyarahkan dalam agenda rutin MGMP Matematika SMA Kabupaten Kubu Raya.

Belajar matematika harus melalui proses yang bertahap dari konsep yang sederhana ke konsep yang lebih kompleks. Setiap konsep matematika dapat dipahami dengan baik jika pertama-tama disajikan dalam bentuk konkrit (Fadillah, 2017). Menurut Dienes (Hudojo, 1998) dikatakan bahwa setiap konsep atau prinsip matematika dapat dimengerti secara sempurna hanya jika pertamatama disajikan kepada peserta didik dalam bentuk-bentuk konkret. Dengan demikian sangatlah penting bagi guru matematika memanipulasi objek-objek matematika yang abstrak menjadi konkrit. Ruseffendi (1992) mengungkapkan bahwa alat peraga adalah alat untuk menerangkan atau mewujudkan konsep matematika sehingga materi pelajaran yng disajikan mudah dipahami oleh siswa.

Matematika dengan permasalahan yang cukup komplek membuat penulis berinisiatif ikut serta dalam berdiskusi dan menawarkan solusi. Berdasarkan hasil wawancara dengan beberapa guru di MGMP Matematika SMA Kabupaten Kubu Raya yang dilakukan pada bulan September 2017, diperoleh informasi bahwa pembelajaran matematika yang dilaksanakan selama ini sangat jarang menggunakan media, khususnya yang berupa alat peraga ataupun media-media inovatif lainnya. Siswa belajar matematika lebih banyak melalui penjelasan secara langsung oleh guru yang didominasi dengan pemberian ceramah. Padahal sejak siswa di SD sudah didominasi dengan ceramah, sehingga banyak hasil penelitian terkait minat dan motivasi belajar siswa terhadap matematika yang mengatakan minat dan motivasi belajar siswa terhadap pembelajaran matematika masih saja rendah. Lebih dalam menelisik penyebab dari rendahnya hasil tersebut diperoleh sebagian besar siswa merasa pembelajaran matematika adalah mata pelajaran yang ditujukan kepada siswa-siswa yang memiliki kecerdasan tinggi saja. Hal 
tersebut dikarenakan metode ceramah, cenderung memberikan kesempatan kepada siswa yang pintar saja untuk aktif dalam pembelajaran.

Guru harusnya memberikan kesempatan kepada semua siswa menunjukkan kecerdasannya, karena tiap siswa memiliki kecerdasan yang berbeda-beda. Terkadang ada siswa yang dapat paham dengan praktek melalui gerak, gestur, stimulasi atau ilustrasi. Oleh karena itu, perlu ada variasi pembelajaran terutama penggunaan media sebagai bentuk ilustrasi materi pembelajaran atau praktek penerapan materi. Matematika SMA dapat dikatakan matematika yang cukup tinggi keabstrakannya. Seorang guru matematika di salah satu SMA di Kabupaten Kubu Raya sangat kesulitan untuk melakukan variasi pembelajaran terutama memunculkan ide penggunaan media atau alat peraga konkret dalam pembelajaran matematika.

Penggunaan media pembelajaran merupakan salah satu factor yang mempengaruhi keberhasilan belajar matematika siswa (Putra dalam Setyadi dan Qohar, 2017:1). Kehadiran media pembelajaran sangat membantu siswa yang sedang dalam fase operasional konkret dalam memahami materi yang bersifat abstrak atau kurang mampu dijelaskan dengan bahasa verbal. Kerumitan bahan yang akan disampaikan pada anak didik juga dapat disederhanakan dengan bantuan media pembelajaran sehingga peserta didik dapat lebih cepat dalam memahami materi pelajaran (Batubara, 2015). Menurut Karimah, dkk (2017:10) proses pembelajaran matematika akan menjadi lebih menyenangkan dan interaktif, dapat dilakukan dengan cara menggunakan media pembelajaran. Minat siswa pada materi tertentu akan tumbuh dan berkembang jika diimbangi dengan pemilihan media yang tepat dalam proses pembelajaran di kelas. Hal ini sependapat dengan apa yang dikemukakan oleh Hamalik (dalam Arsyad, 2011) bahwa keinginan dan minat yang baru pada suatu materi tertentu akan muncul dengan sendirinya jika dalam proses pembelajaran digunakan suatu media pembelajaran. Selain itu, penggunaan media pembelajaran tersebut dapat memunculkan motivasi dan rangsangan kegiatan belajar bahkan dapat mempengaruhi kondisi psikologis siswa pada proses pembelajaran. Beberapa pernyataan tersebut menunjukkan bahwa dalam proses pembelajaran perlu suatu 
media pembelajaran yang dapat memotivasi, menumbuhkan bahkan meningkatkan hasil belajar siswa atau peserta didik dalam semua proses pembelajaran. Secara khusus pada matematika sangat mendukung penggunaan suatu media pembelajaran dikarenakan sifat matematika itu sendiri yaitu keabstrakan. Dengan adanya media pembelajaran dalam proses pembelajaran matematika, seorang pendidik dapat mengkonkritkan abstraknya matematika. Namun, yang menjadi kendala masih banyak pendidik yang belum mumpuni dalam membuat suatu media pembelajaran yang menarik dan interaktif. Sehingga pembelajaran matematika hanya bisa menggunakan media sederhana saja yang selama ini sering digunakan.

Permasalahan-permasalahan tersebut jika tidak segera dicarikan solusi, tentu akan mengakibatkan pembelajaran matematika tidak akan pernah menjadi pelajaran yang disenangi maupun disukai. Oleh karena itu, MGMP Matematika SMA di Kabupaten Kubu Raya bersama dengan tim pelaksana PPM memandang perlu untuk mengadakan kegiatan PPM yang melibatkan para guru di daerah ini. Hal ini karena para guru di daerah ini sangat memerlukan bimbingan untuk menggunakan media pembelajaran, agar dapat mengembangkan kemampuan profesionalisme mereka, sehingga dapat meningkatkan kualitas hasil belajar matematika. Media yang dikembangkan dalam pembelajaran matematika pada kegiatan PPM yang akan dilaksanakan adalah media materi trigonometri meliputi trigamaster, papan sudut rangkap dan klinometer.

\section{METODE}

Kegiatan PKM ini berupa pelatihan penggunaan media pembelajaran matematika pada MGMP Matematika SMA Kubu Raya. Kegiatan ini dilaksanakan di Aula Al Fithyan School Kubu Raya Jalan Raya Kakap Pal 7. Peserta kegiatan PKM ini adalah guru matematika yang tergabung dalam MGMP Matematika SMA Kubu Raya, yang berjumlah 13 orang.

Kegiatan pengabdian pada masyarakat dilaksanakan berdasarkan analisis situasi terlebih dahulu, yaitu (1) kebutuhan calon mitra sebagai anggota masyarakat, (2) permasalahan yang terjadi pada calon mitra, kemudian setelah 
diputuskan mitra yang menjadi target dilanjutkan pada pengkajian solusi yang akan ditawarkan. Mitra yang sangat membutuhkan dalam hal ini adalah guru matematika SMA yang tergabung dalam MGMP Matematika SMA Kabupaten Kubu Raya. Oleh karena itu, pelaksanaan kegiatan pengabdian pada masyarakat menargetkan guru matematika SMA Kubu Raya mampu menggunakan media pembelajaran matematika dalam hal ini trigamaster, papan sudut ganda, dan klinometer. Selain itu, target tambahan kegiatan yaitu guru-guru memahami cara membuat alat-alat tersebut.

Metode pelaksanaan kegiatan PPM ini dilakukan dengan mengadopsi langkah-langkah action research yang terdiri dari 4 (empat) tahapan, yaitu: perencanaan tindakan, observasi dan evaluasi, dan refleksi. Kegiatan yang dilakukan pada tahap perencanaan adalah sebagai berikut. (1) Sosialisasi program PPM pada sekolah mitra. (2) Pertemuan tim musyawarah guru mata pelajaran matematika. (3) Penyusunan program pelatihan.

Kegiatan selanjutnya adalah pemberian tindakan. Tindakan dalam kegiatan ini berupa implementasi program. Kegiatan-kegiatan yang dilakukan dalam implementasi program adalah: (1) menginformasikan atau mengenalkan pada guru tentang media pembelajaran matematika untuk memudahkan pemahaman siswa; (2) mendemonstrasikan teknologi/ cara pembuatan media pembelajaran matematika; (3) pelatihan cara penggunaan media pembelajaran dalam pembelajaran matematika dalam pertemuan MGMP; (4) praktek penggunaan media pembelajaran di kelas pada sekolah mitra, dengan guru-guru lainnya sebagai pengamat.

Kegiatan berikutnya adalah tahap observasi. Observasi dilakukan terhadap proses pembelajaran dengan menggunakan media pembelajaran matematika oleh para guru mitra. Instrumen yang digunakan berupa catatan lapangan. Beberapa hal yang diobservasi adalah kendala-kendala dan kelemahan-kelemahan yang muncul dalam proses pembuatan media pembelajaran di lapangan maupun dalam proses penggunaan di kelas. Tahap terakhir adalah refleksi. Refleksi dilakukan terhadap kegiatan yang telah dilaksanakan. Hal ini dilakukan dengan langkah-langkah sebagai berikut: (1) mengevaluasi kendala-kendala dan kelemahan-kelemahan 
yang muncul dalam penggunaan media pembelajaran matematika pada penerapan pembelajaran di kelas; (2) hasil evaluasi akan digunakan untuk memperbaiki kekurangan-kekurangan yang ada dalam media pembelajaran.

\section{HASIL DAN PEMBAHASAN}

Kegiatan pelatihan penggunaan media ini dimulai dengan pemberian materi tentang Penggunaan Media Pembelajaran dalam Pembelajaran Matematika di SMA". Setelah penjelasan materi, dilanjutkan dengan tanya jawab peserta pada nara sumber.

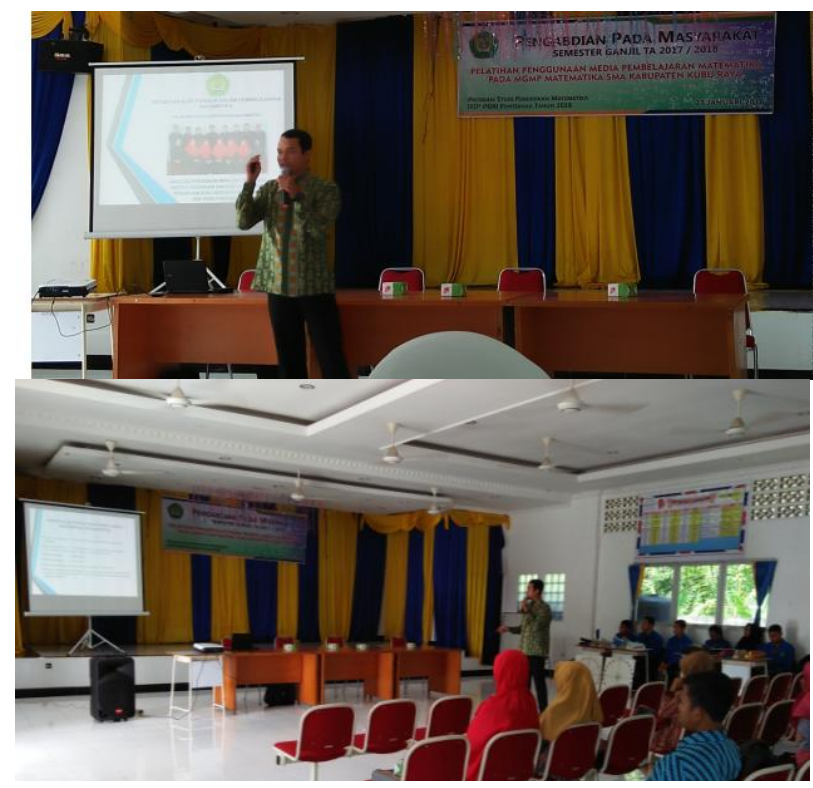

\section{Gambar 1. Narasumber Pelatihan}

Kegitan dilanjutkan dengan mempraktekkan bagaimana menggunakan tiga media pembelajaran, dalam hal ini tim PKM dibantu oleh 6 orang mahasiswa. Beberapa alat peraga yang dipraktekkan penggunaannya dalam pelatihan ini yaitu: Trigamaster, papan koordinat, klinometer. Penjelasan penggunan alat peraga diawali dengan menjelaskan konsep matematika apa yang akan diajarkan dengan alat peraga tersebut, kemudian dilanjutkan dengan cara menggunakan alat peraga tersebut. 


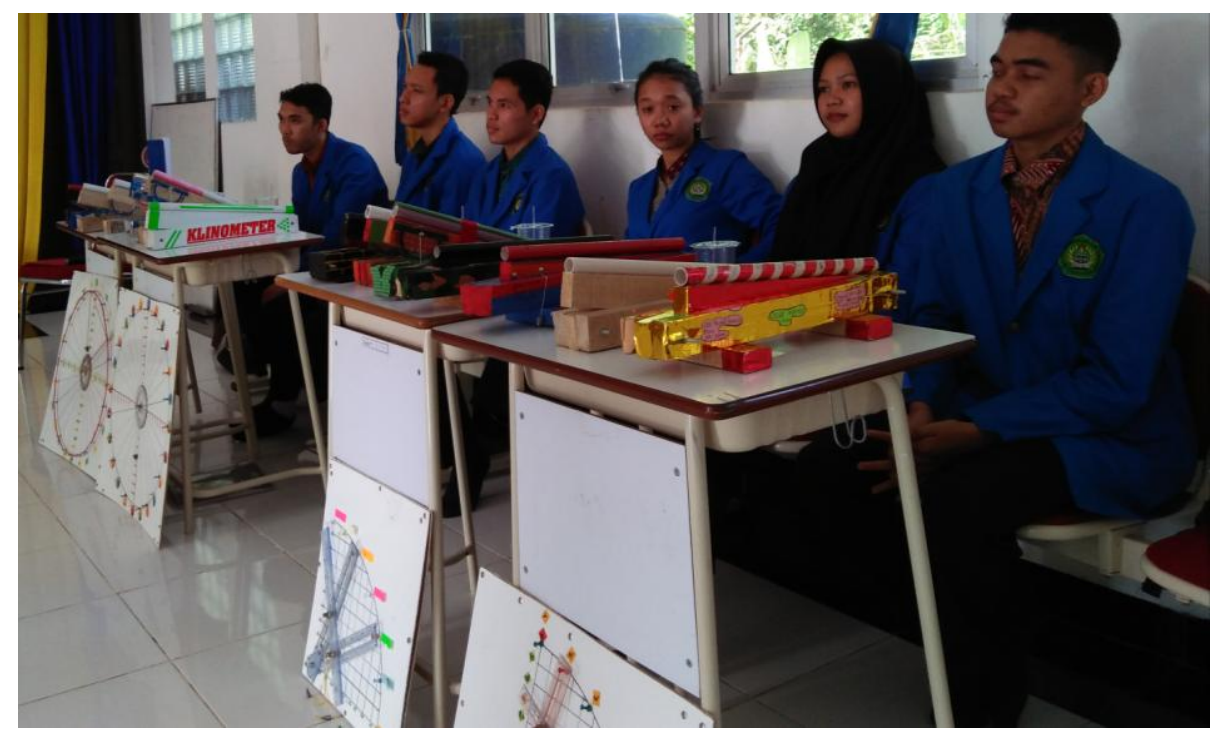

Gambar 2. Alat Peraga Trigonometri

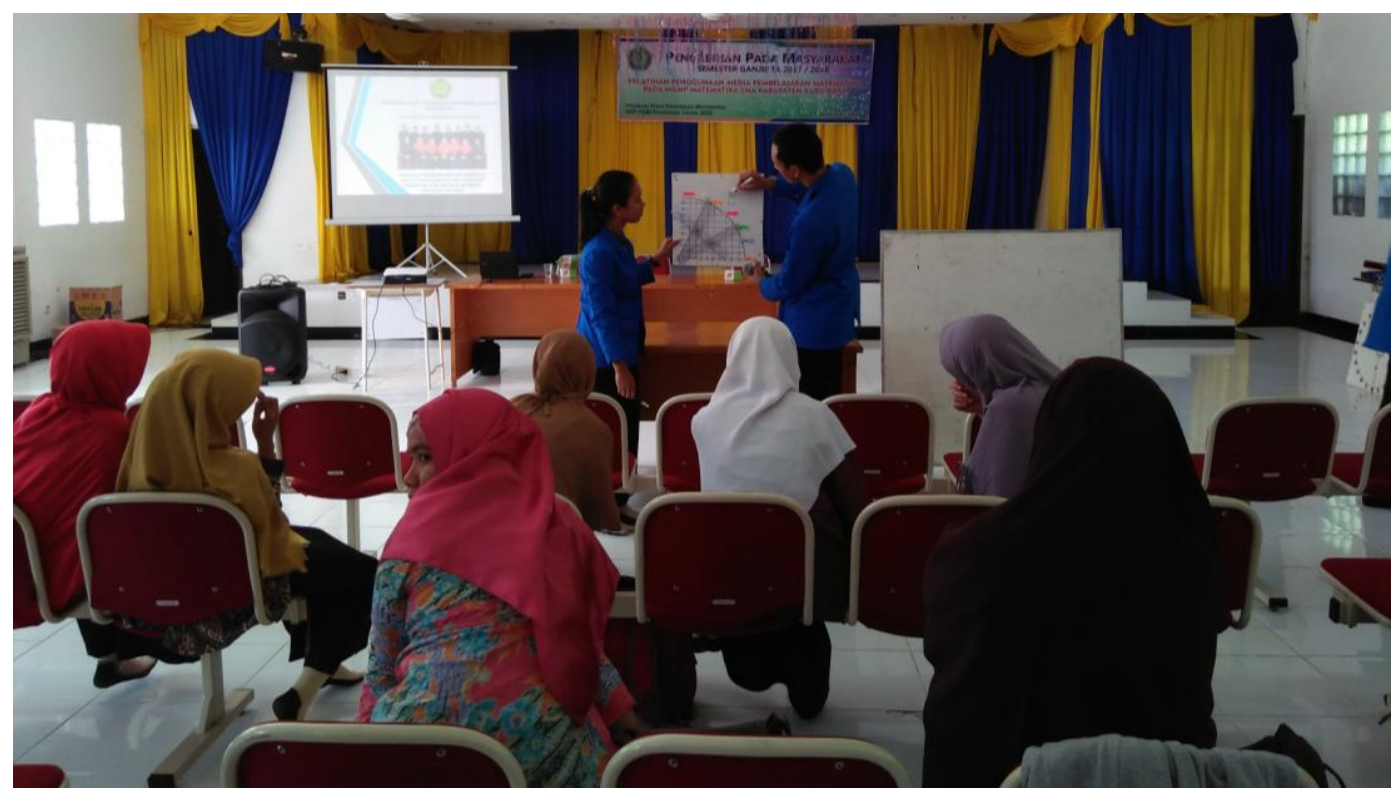

Gambar 3. Demonstrasi Alat Peraga

Respon peserta pelatihan sebagian besar merasa puas terhadap materi seminar dan pelatihan. Terdapat 2 orang responden merasa sangat puas dan 10 responden merasa puas, yang rata-rata pada skala 3. Materi, metode serta efisiensi waktu sebagian besar memberikan penilaian pada skala 5. Saran terhadap materi dari responden yaitu tulisan pada tampilan diperbesar. Peserta juga merasa puas dengan gaya bahasa, kelas pelatihan juga menyenangkan dengan skala yang diberikan pada skala 4. Saran terhadap pemateri, responden menyarankan untuk pemateri lebih dari satu agar lebih banyak mendapatkan ilmu dan pengetahuan. 
Selain itu, komentar yang diberikan adalah mahasiswa yang mendemontrasikan alat peraga cukup jelas dalam menyampaikan langkah-langkah penggunaan alat peraga.

Sarana dan prasarana pelatihan menurut responden berada pada skala 4 . Terdapat 7 responden memberikan penilaian dengan rata-rata 5 dan sisanya memberikan penilaian dengan rata-rata 4. Secara umum peserta merasa puas dengan kegiatan pelatihan yang telah dilaksanakan. Hal tersebut ditunjukkan oleh peserta yang menginginkan kegiatan diadakan secara rutin, dengan kegiatan yang berbeda. Media yang digunakan diharapkan berbasis IT, mengingat jaman yang sudah mengalami kemajuan teknologi.

Kegiatan PKM diakhiri dengan penyerahan alat peraga kepada Ketua MGMP Matematika SMA Kubu Raya sebanyak 17 alat peraga yang diperagakan selama pelatihan. Alat peraga ini diharapkan dapat digunakan oleh guru-guru matematika di SMA Kubu Raya untuk meningkatkan pemahaman konsep matematika siswa mengenai materi trigonometri di sekolah tersebut.

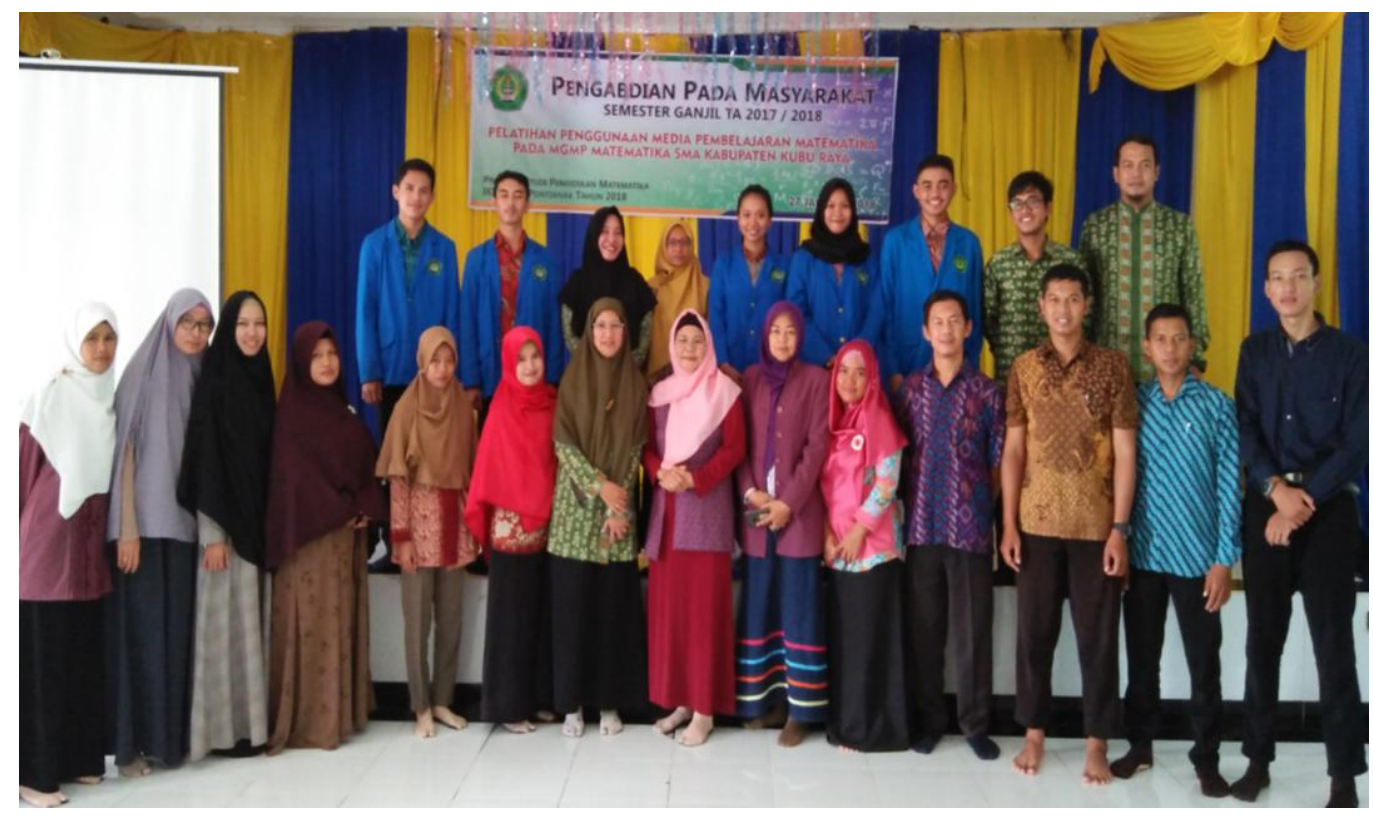

Gambar 4. Foto Bersama Tim PKM dan Peserta Pelatihan

\section{SIMPULAN}

Kegiatan pengabdian kepada masyarakat yang berupa pelatihan penggunaan media pembelajaran matematika pada MGMP Matematika SMA Kubu Raya ini 
dapat disimpulkan yaitu sebagai berikut: (1) kegiatan pelatihan memberikan berjalan sesuai dengan yang direncanakan, respon peserta juga memuaskan terutama pada saat penyampaian materi dan pendemontrasian, sedangkan pada pemateri dan peraga media respon peserta merasa sangat memuaskan. Prasarana yang cukup lengkap menambah nilai kepuasan peserta dalam mengikuti pelatihan; (2) kegiatan pelatihan ini perlu diadakan kembali untuk alat-alat peraga lainnya sehingga dapat menambah pengetahuan yang lebih banyak lagi, serta menambah profesionalitas guru.

\section{UCAPAN TERIMA KASIH}

Terima kasih diucapkan kepada IKIP PGRI Pontianak atas dana Pengabdian kepada Masyarakat tahun anggaran 2017 yang diberikan dan Al Fithyan School Kubu Raya sebagai mitra dalam kegiatan pengabdian.

\section{DAFTAR PUSTAKA}

Fadillah, S., Susiaty, U.D., \& Ardiawan, Y. 2017. "Pelatihan Penggunaan Media Pembelajaran Matematika pada Sekolah Dasar di Kecamatan Pontianak Barat". GERVASI. Vol. 1, no.1, hlm. 1-9.

Hudojo, H. 1998. Mengajar Belajar Matematika. Jakarta: Depdikbud.

LPKM. 2017. Buku Panduan Pelaksanaan Pengabdian Kepada Masyarakat IKIP PGRI Pontianak. Pontianak: LPKM.

Ruseffendi, E.T. 1992. Pembelajaran Matematika Inovatif. Jakarta: Bina Aksara.

Setyadi, D., \& Qohar, A. 2017. "Pengembangan Media Pembelajaran Matematika Berbasis Web pada Materi Barisan dan Deret". Jurnal Matematika KreatifInovatif. Vol. 8, no.1, hlm. 1-7.

Batubara, H.H. 2015. "Pengembangan Media Pembelajaran Interaktif pada Materi Operasi Bilangan Bulat”. Jurnal Madrasah Ibtidaiyah. Vol. 1, no.1, hlm. 112.

Karimah, A.A., Rusdi., \& Fachruddin, M. 2017. "Efektifitas Media Pembelajaran Matematika Menggunakan Software Animasi Berbasis Multimedia Interaktif Model Tutorial pada Materi Garis dan Sudut untuk Siswa 
GERVASI: Jurnal Pengabdian kepada Masyarakat

Vol. 3, No. 1, Juni 2019

ISSN 2598-6147 (Cetak)

ISSN 2598-6155 (Online)

SMP/MTs Kelas VII'. Jurnal Penelitian Pembelajaran Matematika Sekolah. Vol. 1, no.1, hlm. 9-13.

Arsyad, A. 2011. Media Pembelajaran. Jakarta: PT Raja. 